Article

\title{
Urban Planning Academics: Tweets and Citations
}

\author{
Thomas W. Sanchez \\ Urban Affairs and Planning, Virginia Tech, Arlington, VA 22203, USA; E-Mail: sanchezt@vt.edu
}

Submitted: 4 October 2020 | Accepted: 26 November 2020 | Published: 24 February 2021

\begin{abstract}
This article discusses the relationship between Twitter usage and scholarly citations by urban planning academics in the U.S. and Canada. Social media and academic publications may be considered separate activities by some, but over the past decade there has been a convergence of the two. Social media and scholarship can be complementary not only when social media is used to communicate about new publications, but also to gather research ideas and build research networks. The analysis presented here explores this relationship for urban planning faculty using data for faculty who had active Twitter accounts between March 2007 and April 2019. Measures of Twitter activity were combined with Google Scholar citation data for 322 faculty with Twitter accounts. As expected, the results highlight that there are different patterns of Twitter activity between junior faculty and senior faculty both in terms of proportions of each rank using Twitter as well as activity levels on the social media platform. The results also suggest that Twitter activity does not have a statistically significant relationship with overall scholarly productivity as measured by citation levels.
\end{abstract}

\section{Keywords}

academic; Canada; citations; Google; planning; research; social media; Twitter; US

\section{Issue}

This article is part of the issue "Innovations and Development in Urban Planning Scholarship and Research" edited by Thomas W. Sanchez (Virginia Tech, USA).

(C) 2021 by the author; licensee Cogitatio (Lisbon, Portugal). This article is licensed under a Creative Commons Attribution 4.0 International License (CC BY).

\section{Introduction}

The emergence of social media has created new approaches for academics to engage with others about research topics, build new collaborations, and utilize new ways to communicate their scholarly outcomes. Twitter is one of the primary forms of social media used by academics to enhance productivity and elevate scholarly reputation. This study compares urban planning academic's Twitter and scholarly activities to explore these dynamics. Does more time spent on social media correlate with less scholarly output? Or are scholars actively publishing also active on social media as these activities converge? One way to examine this is by comparing levels of Twitter and scholarly 'productivity' for faculty in the planning discipline. This is of interest because scholars wishing to better communicate their research and potentially broaden their audiences. The following briefly reviews the literature on Twitter usage by academics, citations as a measure of productivity, and the relationship between Twitter and citations. A quanti- tative analysis using Twitter and citation activity data for planning academics is then presented that examines this question.

\section{Literature Review}

As with the Internet, some scholars predicted a revolution in information sharing via social media with far reaching benefits to society (Hilbert \& López, 2011; Nie \& Erbring, 2002). These benefits were expected from the shear amount of information that could easily be shared with unlimited geographic reach. At the same time, others warned of an increase in conformity through social influence (Bargh \& McKenna, 2004; Creeber \& Martin, 2008), particularly when certain ideologies are able to dominate broadcast channels and platforms. For higher education social media represented a significant change and an opportunity to increase communication beyond the academy (Kimmons, Veletsianos, \& Woodward, 2017). But concerns have arisen from evidence pointing to the intersection of influence and 
persuasion on social media in propagating misinformation along with trolling, inappropriate language, and a lack of civility common to online commentary (Allcott \& Gentzkow, 2017; Schweitzer, 2014). This calls into question the long-term viability of such platforms as channels for serious academic discourse. Nonetheless, social media provides an added dimension to scholarly communication that is evolving, with academics being encouraged to develop their individual reputations and gain increased visibility in their respective fields. Not only are academics expected to publish, teach, and perform service, but now more than ever, they are urged to promote themselves both within and beyond their institutions (Weller, 2011).

\subsection{Social Media}

There is a growing literature on how and why academics use social media platforms such as Twitter. Twitter is based on short (140 character) messages posted to its platform that also combines hyperlinks, graphics, and tagging. Content is shareable to other platforms, therefore extending its reach even further. While there are many analyses of Twitter activity by academics, analyses of complete academic disciplines are quite rare. One reason for this is that data collection is difficult without standards or conventions capable of accurately identifying users. Similarly, name disambiguation for scholarly publications is challenging, limiting the coverage of academic disciplines, especially those with many faculty. This explains why there are so few empirical analyses of individual disciplines, and why many rely on sparse sampling of social media users (see Thelwall, Tsou, Weingart, Holmberg, \& Haustein, 2013). ORCID and ResearcherID are examples of efforts to address the challenge of author identification by establishing protocols that link authors, affiliations, and scholarly products. These are voluntary systems with less than a majority of academics currently using them. In addition, these systems apply to only scholarly publications and no other types of accounts such as those for social media.

The literature identifies four general categories of Twitter use by academics. These include communications, professional development, self-promotion, and profile management (Carpenter \& Krutka, 2014; Hall, 2014; Jordan, 2019; Veletsianos \& Kimmons, 2013). Kassens-Noor (2012) and Carpenter and Krutka (2014) discuss the potential of Twitter for classroom instruction, but to date there is little evaluation of the practice. The four aspects previously mentioned connect with promotion and tenure criteria that emphasize external visibility (Schimanski \& Alperin, 2018). Promotion and tenure committees often gauge the performance of a candidate by assessing their level of regard within a field based on limited metrics. This includes reviews by external academics, seen as objective, and representing the broader community of the discipline. Some universities, through their promotion and tenure processes and guidelines, are placing value on faculty social media participation (see Cabrera et al., 2017; O'Meara, 2016). Despite the lack of evidence to suggest that institutions actually benefit from these efforts, other than hopes that it serves university public relations.

The capabilities of Twitter to increase communications will continue to evolve across disciplines, platforms, and purposes. In the case of urban planning, benefits can take the form of increasing the volume of planning related discourse. This includes the conversational and 'chat' dimensions of Twitter, as well as virtual communitybuilding (whether real or imagined) as reported by Gruzd, Wellman, and Takhteyev (2011). These conversations also combine 'real life' and virtual forums when Twitter is used in connection with academic conferences. This means that these conversations can extend beyond conferences in space and time, along with creating 'backchannel' communications (Li \& Greenhow, 2015; Weller, Dröge, \& Puschmann, 2011). This is likely true for urban planning academics who are assumed to use Twitter in similar ways as other academics in the social sciences. It is also likely, but too soon to conclude, how the Covid-19 pandemic will impact online communications and academic conferences into the future.

\subsection{Scholarly Citations}

Citation analysis for scholarly evaluation has an extensive literature that considers patterns across disciplines along with offering nuanced discussion of performance metrics (see Glänzel, Moed, Schmoch, \& Thelwall, 2019). Citation analysis is one way to evaluate scholarly activity but is often limited to assessing productivity or output rather than other dimensions such as visibility, reputation, and impact (Sanchez, 2014). The following provides a brief discussion and background on citation analysis and urban planning scholarship for the purposes of the current analysis.

This analysis uses Google Scholar as a source of citation data. There is a substantial body of literature that discusses the application of Google Scholar to citation analysis and make comparisons to Elsevier's Scopus and Thomson Reuter's Web of Science (previously, ISI Web of Knowledge). With its release in 2004, one question about Google Scholar is whether its coverage of scholarly publications can match that of other sources (Falagas, Pitsouni, Malietzis, \& Pappas, 2008; Harzing, 2013a; Meho \& Yang, 2007). Acknowledging that coverage issues are discipline specific, there are many examples of Google Scholar-based citation analyses for particular fields ranging from oncology and condensed matter physics (Bakkalbasi, Bauer, Glover, \& Wang, 2006), to business and economics (Levine-Clark \& Gil, 2008), to health and medical research (Kulkarni, Aziz, Shams, \& Busse, 2009). Most comparisons focus on citation counts for small samples of academics while others compare citation rates for academic journals (Moussa \& Touzani, 2010). Other meta-analyses are helpful in understanding 
patterns in bibliometric differences among data sources and analysis methods (see López-Cózar, Orduña-Malea, \& Martín-Martín, 2019).

There are particular aspects of citation databases that emerge from comparative analyses including the age range of cited publication materials, languages included, types of materials cited, and disciplinary coverage (Harzing, 2013a ; Kousha \& Thelwall, 2007). It is interesting to note that most of the analyses comparing Google Scholar with Scopus and Web of Science concentrate on citation totals and not on the accuracy of these data sources at the publication or author level. In other words, to determine how accurate citation totals are for an individual, the actual list of scholarly products (i.e., those listed in a CV) should be compared to the results extracted from the citation databases for an author. This is currently infeasible without a comprehensive source of accurate CV data that can be matched to publication records in Scopus, Web of Science, or Google Scholar. An effective author cross-referencing and identification system would help to solve this problem.

To date there are few bibliometric analyses specifically on urban planning scholarship. Examples of such analyses for urban planning academics include Stiftel, Rukmana, and Alam (2004), followed several years later by Sanchez (2017), Pojani, Olvera-Garcia, Sipe, and Byrne (2018), Stevens, Park, Tian, Kim, and Ewing (2019), and Sanchez (2020). The bibliometric literature has long recognized the differential rates of citation by topics, following the assumption that certain sub-fields are more popular, have more publications and therefore greater chances of citation (see Bornmann, Schier, Marx, \& Daniel, 2012). In their analysis of factors effecting urban planning citations, Stevens et al. (2019) included variables indicating whether the publication topic was related to one of 13 selected subtopics. They found that compared to 'transportation,' nearly all other sub-fields were cited less frequently, with many of the regression coefficients being insignificant. Compared to Sanchez (2020), the findings of Stevens et al. (2019) were less comprehensive because of the sample size (580 article characteristics compared to nearly 15,000 publication titles by Sanchez, 2020) and the topic classification methods. Sample size issues likely introduce bias by over or under-representing certain planning topics, and topic classification methods provide varied outcomes, especially given the multi-disciplinarity of urban planning research. The analysis presented here relies on citation totals and the $\mathrm{H}$-Index for each of the faculty having Twitter accounts and does not normalize for topics due to the complexity of matching Tweet topics with publication topics (see Sanchez, 2020, for an in-depth analysis of planning topics and citation levels).

\subsection{Tweets and Citations}

Along with Twitter usage and academic citations for planning academics, a third dimension is the relationship between Twitter and citations, some of which was discussed previously. One challenge is that while the vast majority of planning academics produce cited scholarship, only about one-third of them are active users of Twitter. So, any analysis of Twitter and citation activity will contend with the question of whether active scholars are more likely to be active on social media or vice versa. One theme among the bibliometric and Altmetrics literatures is whether tweets predict citation activity-that somehow tweets effectively draw attention to publications, and therefore generate citations. To date the evidence of this relationship is weak, but it is safe to assume that academics will continue using whatever methods are available to increase the visibility of their publications to hopefully increase citation levels (see de Winter, 2015; Haustein, Peters, Sugimoto, Thelwall, \& Larivière, 2014).

\section{Methodology}

To examine Twitter usage by urban planning academics, data were obtained from two primary sources. A list of 1,107 urban planning faculty names from 106 universities across the U.S. and Canada maintained by Sanchez (2017), were searched using the Twitter's API to find associated accounts. Each query result was then reviewed to confirm it was being used for professional purposes by an individual faculty member. Accounts were considered being used for professional purposes if the user profile contained a professional title (e.g., professor), mention urban planning or an area of expertise (e.g., transportation, housing, environment), or employer's name (i.e., university name or academic department). In some cases, accounts were included when these criteria were not met but the content of tweets from the account were related to urban planning topics. Individuals who did not have their own Twitter accounts, but instead used organizational accounts, were not included. Organizational accounts accessed by multiple people do not represent the activities of the individual academic of interest and may inflate the number of tweets attributed to an individual. Because citations are individually based, Twitter activity for the analysis should be as well. The proportion of planning academics using Twitter was similar to that found by Mohammadi, Thelwall, Kwasny, and Holmes (2018) for academics in a variety of disciplines and being in the range of $30 \%$ to $35 \%$. Their estimates were based on sampling, where the current analysis represents the complete population of academic planning Twitter users.

A total of 322 Twitter accounts were identified from the list of over 1,100 urban planning faculty. Lists of all profiles, tweets, followers, and friends were obtained through the Global Event and Trend Archive Research Project (National Science Foundation projects IIS-1619028 and 1619371). This included all account activity from March 2007 to April 2019 for these 322 accounts. The first part of the analysis focuses on general characteristics of the faculty Twitter users including: 
age of accounts, frequency of participation, and userengagement levels. These characteristics were also considered relative to academic rank. The next step was to collect the publication records for the same group of urban planning academics. Citation data were assembled from Google Scholar Citation Profiles and Harzing's Publish or Perish (also drawn from Google Scholar Citation data). Of the 322 planning faculty with Twitter accounts in 2019, 236 had Google Scholar Citation Profiles containing citation totals and $\mathrm{H}$-Indices. For the other 86 faculty without profiles, the data were compiled using Publish or Perish.

The Twitter and citation data were then matched for the 322 faculty to complete the dataset. It was expected that comparing Twitter activity and citation metrics would reveal a distribution of faculty types falling into the quadrants shown in Figure 1 . As previously discussed, there are a variety of interpretations for these categories related to levels of productivity as well as potential citation benefits of tweeting about publications. It was not expected that this analysis could detect or explain these interactions because the analysis is only looking at general levels of activity and not at the individual publication level. This would also involve tracking the timing of tweets with online or print publications. The question is whether tweets effect citations or do citations result in more Twitter activity. To examine this at a fine level of granularity means the analysis would need dates of tweets (which are available) and dates of citations (which are not available-other than a volume, and issue number in the case of journal articles). There can be a relatively long time horizon for citations, beyond just the time of publication, often several years later. Another issue is how tweets can reference publications, whether by title, by author, or DOI. DOI is likely the best because it links directly to a publication. Unfortunately, there is no standard way that tweets reference academic publications so such an enumeration is currently unreliable.

An expectation associated with the quadrants shown in Figure 1 is that more senior faculty have higher cita-

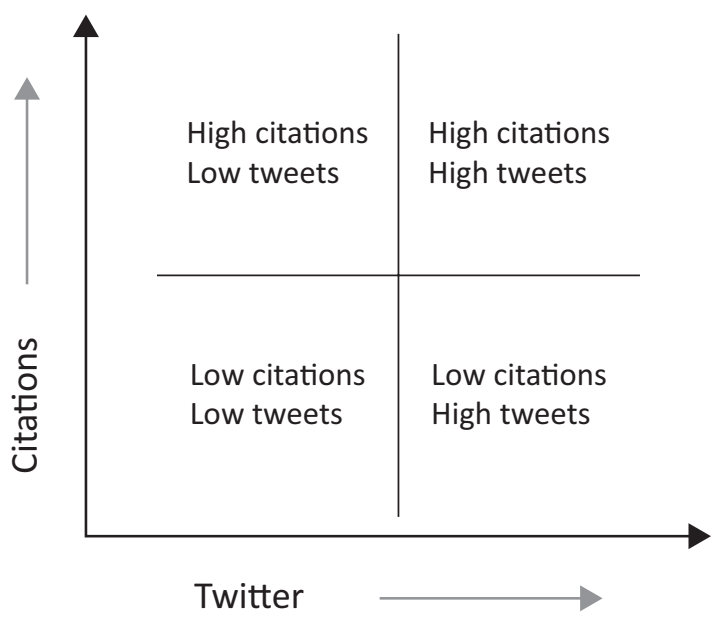

Figure 1. Faculty citation and tweet activity levels. tion counts and lower levels of Twitter activity due to less familiarity with social media, and 'youth' being associated with lower citation levels and higher levels of Twitter usage. It is possible that both junior and senior faculty tweet often, but not possible (or very rare) for junior faculty to have high levels of citations. The results of the analysis will explore these patterns in part, to understand the convergence of social media and scholarship, particularly by academic rank. A regression model was used to estimate the association of Twitter activity and scholarly productivity. The model controls for seniority (rank), years since completion of a PhD, and whether the person had a Google Scholar Citation Profile. A binary variable for Google Scholar Profiles is used to control for the source of citation data. Errors do exist in profiles such as inclusion of publications or citations not belonging to an author which inflate totals. In addition, publications or citations can be missing from profiles, therefore underreporting citation metrics. Harzing (2013b) addresses issue and reports that systematic errors (particularly for inflated citation totals) do not appear to be a concern.

\section{Results}

Of the 322 urban planning faculty with Twitter accounts in 2019, a small number had not yet tweeted, but all of them had followers and friends. A 'follower' or 'friend' indicates the direction of relation and how posts will automatically appear in a user's feed (i.e., list of tweets). The number of followers and friends are also higher among junior faculty. The earliest planning faculty Twitter account was established in 2007 and there were a total of 560,119 tweets posted by urban planning faculty between March 2007 and April 2019. Planning faculty Twitter users are nearly split evenly by rank for assistant, associate, and full professors, and the age of all accounts average six to seven years (Table 1). In 2019, $26.5 \%$ of planning faculty were assistant professors, $33.1 \%$ were associate professors, and $40.4 \%$ were full professors. Junior faculty tweet (or retweet) more frequently than senior faculty, with a median of slightly more than once per week. It should be noted that the distributions are skewed, and therefore, the median values are more reliable indicators of central tendency. Tweeting activity (tweets per month) were analyzed to find the prevalence of outliers (those greater than three standard deviations from the mean). The data show that there were actually a small number of 'power users,' identifying three assistant professors, two associate professors, and one full professor. These individuals were left in the dataset to because their other characteristics were not anomalous. And as expected, the citation counts and $\mathrm{H}$-Indices for senior faculty are higher than those of junior faculty.

The results are interesting in terms of the relative uniformity of indicators for what can be seen as the convergence of social media and scholarly productivity. Table 2 shows that these two activities are not exclusive, showing technology usage (e.g., social media) by 
Table 1. Descriptive statistics by academic rank.

\begin{tabular}{|c|c|c|c|c|}
\hline Position & & $\mathrm{N}$ & Mean & Median \\
\hline \multirow[t]{8}{*}{ All Professors } & Account age (mos.) & 322 & 78.0 & 81.1 \\
\hline & No. of Tweets & 322 & 1739.5 & 215.5 \\
\hline & No. of Followers & 322 & 655.4 & 202.0 \\
\hline & No. of Friends & 322 & 456.7 & 177.5 \\
\hline & Followers-to-friends ratio & 322 & 3.1 & 1.0 \\
\hline & Tweets per month & 322 & 19.8 & 3.3 \\
\hline & Citations & 322 & 1545.4 & 494.5 \\
\hline & $\mathrm{H}$-Index & 322 & 13.1 & 10.0 \\
\hline \multirow[t]{8}{*}{ Assistant Professor } & Account age (mos.) & 116 & 77.8 & 79.8 \\
\hline & No. of Tweets & 116 & 1299.9 & 298.5 \\
\hline & No. of Followers & 116 & 405.7 & 238.0 \\
\hline & No. of Friends & 116 & 491.9 & 284.5 \\
\hline & Followers-to-friends ratio & 116 & 1.2 & 0.8 \\
\hline & Tweets per month & 116 & 14.6 & 4.5 \\
\hline & Citations & 116 & 250.1 & 133.0 \\
\hline & H-Index & 116 & 6.0 & 5.0 \\
\hline \multirow[t]{8}{*}{ Associate Professor } & Account age (mos.) & 105 & 73.9 & 80.2 \\
\hline & No. of Tweets & 105 & 1493.8 & 267.0 \\
\hline & No. of Followers & 105 & 642.8 & 204.0 \\
\hline & No. of Friends & 105 & 435.4 & 191.0 \\
\hline & Followers-to-friends ratio & 105 & 2.3 & 1.0 \\
\hline & Tweets per month & 105 & 18.9 & 4.0 \\
\hline & Citations & 105 & 913.6 & 466.0 \\
\hline & H-Index & 105 & 11.5 & 10.0 \\
\hline \multirow[t]{8}{*}{ Professor } & Account age (mos.) & 101 & 82.7 & 83.9 \\
\hline & No. of Tweets & 101 & 2500.0 & 106.0 \\
\hline & No. of Followers & 101 & 955.4 & 182.0 \\
\hline & No. of Friends & 101 & 438.5 & 114.0 \\
\hline & Followers-to-friends ratio & 101 & 6.1 & 1.4 \\
\hline & Tweets per month & 101 & 26.6 & 1.6 \\
\hline & Citations & 101 & 3689.7 & 2314.0 \\
\hline & H-Index & 101 & 23.0 & 21.0 \\
\hline
\end{tabular}

younger faculty and significant overall productivity being attributed to more senior faculty. The characteristics of faculty falling into Quadrant 1 (higher levels of citations and lower levels of Twitter activity) tend to be older faculty members (by years since their PhD) as well as their rank. $62 \%$ of faculty in Quadrant 1 are full professors and $9 \%$ are assistant professors (Table 2 ). The proportion of assistant professors in Quadrants 1 and 2 are higher than expected, because these represent the high citation groups, however, the same is true for the low citation group which also have full professors among them (Quadrants 3 and 4). Overall, it is interesting to note the evenness of the distribution between Twitter and citation activity by rank.

Table 2. Twitter and Citation Levels Matrix.

\begin{tabular}{lccrr}
\hline Quadrant & Years & Assistant & Associate & Full \\
\hline 1. High C, Low T (79) & 23.5 & $9 \%$ & $29 \%$ & $62 \%$ \\
2. High C, High T (82) & 19.1 & $18 \%$ & $35 \%$ & $46 \%$ \\
3. Low C, High T (79) & 9.6 & $62 \%$ & $33 \%$ & $5 \%$ \\
4. Low C, Low T (82) & 12.6 & $55 \%$ & $33 \%$ & $12 \%$ \\
Total (322) & 16.2 & $36 \%$ & $33 \%$ & $31 \%$ \\
\hline
\end{tabular}

Note: The threshold for 'high' versus 'low' is the median value for all faculty. 
Finally, Table 3 presents the results of a regression analysis predicting scholarly productivity as measured by citation counts. Of particular interest was the relationship between Twitter activity (total and monthly tweets) and citation totals. The model controlled for seniority (rank), years since completion of a PhD, whether the person had a Google Scholar Citation Profile. The model explained approximately $50 \%$ of the variation in citation counts (natural log of total citations). While rank and years were statistically significant, the Twitter activity variable (tweets per month) was not. As expected, years as a professor was positively correlated with total citations, as was the use of Google Scholar Citation Profiles. While the coefficient for having a profile was positive, it cannot be stated definitively why this is the case. Two possible explanations are that profiles contain inflated citation metrics, or, that academics with high citation activity are interested in tracking their own metrics and represent self-selection within the population. Further analysis beyond the scope of this analysis would be needed to further assess this pattern. The model shown in Table 3 provided the highest level of explanatory value compared to alternative models using total citations and citations per year as dependent variables. In addition, each model was tested with total tweets instead of tweets per month as independent variables. One interpretation of these results is that planning faculty who tweet more do not publish less or have fewer citations, nor do they have more.

\section{Conclusions}

As social media is more commonly used by academics, one question is whether the effort put toward one displaces the efforts into the other, therefore impacting how faculty allocate their efforts. Urban planning is a small academic discipline with approximately 1,100 faculty in the U.S. and Canada. Of these faculty, about onethird actively use Twitter, similar to other fields and disciplines. However, there are no other empirical analyses of disciplines allied with planning such as public administration, urban studies, public policy, etc., to make comparisons. Some academic literature suggests that Twitter activity can be beneficial to scholarly communications, but these studies rely on small samples and lack data for compete disciplines like the analysis presented here.

Overall, the results of this analysis show that younger faculty are more likely to be on Twitter compared to senior faculty. Overall, $39.3 \%$ of assistant professors, $39.3 \%$ of associate professors, and $22.4 \%$ of full professors were using Twitter. On average, junior faculty are also more active on the platform. As expected, senior faculty have produced more publications and therefore are more highly cited. The higher levels of Twitter activity do not appear related to more citations, nor is it associated with fewer citations for each of the three academic ranks.

The literature suggests that the benefits of Twitter for faculty are potentially related to better scholarly communications and network building despite little evidence to support this. Previous research has examined these applications for other academic disciplines, but none to date for urban planning. Along with the data examined in this analysis, more can be learned about personal expectations and experiences through additional data collection directly from planning faculty, such as through survey research. Such research can better answer questions about motivations for using Twitter and perceived benefits associated with professional roles, responsibilities, and expectations.

One limitation of the analysis is that it represents a single point in time, not able to illustrate the process of change, especially for social media (i.e., Twitter) adoption as it occurred over time. An analysis over time and a snapshot like the one presented here (despite being limited in scope), can in fact highlight that there are different types of faculty with different roles, responsibilities, and professional styles. Future research should explore the relationship between social media activities, scholarly productivity, and promotion and tenure. This would involve additional data collection in the form of faculty

Table 3. Regression results.

\begin{tabular}{|c|c|c|c|c|c|}
\hline & $\begin{array}{c}\text { Unstandardized } \\
\text { Coefficients } \\
\text { B }\end{array}$ & $\begin{array}{l}\text { Standardized } \\
\text { Coefficients } \\
\text { Std. Error }\end{array}$ & Beta & $\mathrm{t}$ & \\
\hline (Constant) & 5.616 & 0.390 & & 14.413 & $<0.001$ \\
\hline Google Scholar Profile (0/1) & 1.632 & 0.181 & 0.368 & 9.030 & $<0.001$ \\
\hline Years & 0.025 & 0.012 & 0.141 & 2.182 & 0.030 \\
\hline Tweets per month & 0.002 & 0.001 & 0.064 & 1.589 & 0.113 \\
\hline Assistant (0/1) & -2.564 & 0.304 & -0.627 & -8.448 & $<0.001$ \\
\hline Associate $(0 / 1)$ & -1.153 & 0.245 & -0.275 & -4.712 & $<0.001$ \\
\hline \multicolumn{6}{|l|}{ Model Summary } \\
\hline & $\mathrm{R}$ & $\mathrm{R}^{2}$ & Adj. $R^{2}$ & SEE & \\
\hline & 0.711 & 0.506 & 0.498 & 1.394 & \\
\hline
\end{tabular}

a. Dependent Variable: $\operatorname{In}$ (Total Cites)

b. Full Professor is omitted variable 
CVs, however, it could yield some interesting findings about dynamics of faculty evaluation and participation on social media platforms such as Twitter. Another path for future research could include the use of Altmetrics to assess academic productivity and online presence. Altmetrics extends beyond social media and has the potential to provide broadened evaluation. Again, the challenge is related to data collection, and how to accurately identify and compile these data for thousands of individuals. The hope is that like the initial promises of the Internet, more data will be within our reach.

\section{Acknowledgments}

The author would like to thank Ziqian (Alice) Song for her assistance with assembling the Twitter data. In addition, the author thanks the three reviewers for their very insightful comments.

\section{Conflict of Interests}

The author declares no conflict of interests.

\section{References}

Allcott, H., \& Gentzkow, M. (2017). Social media and fake news in the 2016 election. Journal of Economic Perspectives, 31(2), 211-236.

Bakkalbasi, N., Bauer, K., Glover, J., \& Wang, L. (2006). Three options for citation tracking: Google Scholar, Scopus and Web of Science. Biomedical Digital Libraries, 3(1). https://bio-diglib.biomedcentral. com/articles/10.1186/1742-5581-3-7

Bargh, J. A., \& McKenna, K. Y. (2004). The Internet and social life. Annual Review of Psychology, 55, 573-590.

Bornmann, L., Schier, H., Marx, W., \& Daniel, H. D. (2012). What factors determine citation counts of publications in chemistry besides their quality? Journal of Informetrics, 6(1), 11-18.

Cabrera, D., Vartabedian, B. S., Spinner, R. J., Jordan, B. L., Aase, L. A., \& Timimi, F. K. (2017). More than likes and tweets: Creating social media portfolios for academic promotion and tenure. Journal of Graduate Medical Education, 9(4), 421-425.

Carpenter, J. P., \& Krutka, D. G. (2014). How and why educators use Twitter: A survey of the field. Journal of Research on Technology in Education, 46(4), 414-434.

Creeber, G., \& Martin, R. (2008). Digital culture: Understanding new media. New York, NY: McGraw-Hill Education.

de Winter, J. C. (2015). The relationship between tweets, citations, and article views for PLOS ONE articles. Scientometrics, 102(2), 1773-1779.

Falagas, M. E., Pitsouni, E. I., Malietzis, G. A., \& Pappas, G. (2008). Comparison of PubMed, Scopus, web of science, and Google scholar: Strengths and weaknesses. The FASEB Journal, 22(2), 338-342.
Glänzel, W., Moed, H. F., Schmoch, U., \& Thelwall, M. (Eds.). (2019). Springer handbook of science and technology indicators. Cham: Springer Nature.

Gruzd, A., Wellman, B., \& Takhteyev, Y. (2011). Imagining Twitter as an imagined community. American Behavioral Scientist, 55(10), 1294-1318.

Hall, N. (2014). The Kardashian index: A measure of discrepant social media profile for scientists. Genome Biology, 15(7). https://genomebiology. biomedcentral.com/articles/10.1186/s13059-0140424-0

Harzing, A. W. (2013a). A longitudinal study of Google Scholar coverage between 2012 and 2013. Scientometrics, 98(1), 565-575.

Harzing, A. W. (2013b). A preliminary test of Google Scholar as a source for citation data: A longitudinal study of Nobel prize winners. Scientometrics, 94(3), 1057-1075.

Haustein, S., Peters, I., Sugimoto, C. R., Thelwall, M., \& Larivière, V. (2014). Tweeting biomedicine: An analysis of tweets and citations in the biomedical literature. Journal of the Association for Information Science and Technology, 65(4), 656-669.

Hilbert, M., \& López, P. (2011). The world's technological capacity to store, communicate, and compute information. Science, 332(6025), 60-65.

Jordan, K. (2019). Separating and merging professional and personal selves online: The structure and processes that shape academics' ego-networks on academic social networking sites and Twitter. Journal of the Association for Information Science and Technology, 70(8), 830-842.

Kassens-Noor, E. (2012). Twitter as a teaching practice to enhance active and informal learning in higher education: The case of sustainable tweets. Active Learning in Higher Education, 13(1), 9-21.

Kimmons, R., Veletsianos, G., \& Woodward, S. (2017). Institutional uses of Twitter in US higher education. Innovative Higher Education, 42(2), 97-111.

Kousha, K., \& Thelwall, M. (2007). Sources of Google Scholar citations outside the Science Citation Index: A comparison between four science disciplines. Scientometrics, 74(2), 273-294.

Kulkarni, A. V., Aziz, B., Shams, I., \& Busse, J. W. (2009). Comparisons of citations in Web of Science, Scopus, and Google Scholar for articles published in general medical journals. JAMA, 302(10), 1092-1096.

Levine-Clark, M., \& Gil, E. L. (2008). A comparative citation analysis of Web of Science, Scopus, and Google Scholar. Journal of Business \& Finance Librarianship, 14(1), 32-46.

Li, J., \& Greenhow, C. (2015). Scholars and social media: Tweeting in the conference backchannel for professional learning. Educational Media International, 52(1), 1-14.

López-Cózar, E. D., Orduña-Malea, E., \& Martín-Martín, A. (2019). Google Scholar as a data source for research assessment. In M. Thelwall, W. Glänzel, U. Schmoch, 
\& H. F. Moed (Eds.), Springer handbook of science and technology indicators (pp. 95-127). Cham: Springer.

Meho, L. I., \& Yang, K. (2007). Impact of data sources on citation counts and rankings of LIS faculty: Web of Science versus Scopus and Google Scholar. Journal of the American Society for Information Science and Technology, 58(13), 2105-2125.

Mohammadi, E., Thelwall, M., Kwasny, M., \& Holmes, K. L. (2018). Academic information on Twitter: A user survey. PloS One, 13(5). https://doi.org/10.1371/ journal.pone.0197265

Moussa, S., \& Touzani, M. (2010). Ranking marketing journals using the Google Scholar-based hg-index. Journal of Informetrics, 4(1), 107-117.

Nie, N. H., \& Erbring, L. (2002). Internet and society: A preliminary report. IT \& Society, 1(1), 275-283.

O'Meara, K. (2016). How scholarship reconsidered disrupted the promotion and tenure system. In E. L. Boyer, D. Moser, T. C. Ream, \& J. M. Braxton (Eds.), Scholarship reconsidered: Priorities of the professoriate, expanded edition (pp. 41-51). Hoboken, NJ: Wiley.

Pojani, D., Olvera-Garcia, J., Sipe, N., \& Byrne, J. (2018). Research productivity of Australian planning academics: A bibliometric analysis. Journal of Planning Education and Research. https://doi.org/10.1177/ 0739456X18804330

Sanchez, T. W. (2014). Academic visibility and the webometric future. Journal of the World Universities Forum, 6(2), 37-52.

Sanchez, T. W. (2017). Faculty performance evaluation using citation analysis: An update. Journal of Planning Education and Research, 37(1), 83-94.

Sanchez, T. W. (2020). The most frequently cited topics in urban planning scholarship. Urban Science, 4(1). https://doi.org/10.3390/urbansci4010004

Schimanski, L. A., \& Alperin, J. P. (2018). The evaluation of scholarship in academic promotion and tenure processes: Past, present, and future. F1000Research. https://doi.org/10.12688/f1000research.16493.1

Schweitzer, L. (2014). Planning and social media: A case study of public transit and stigma on Twitter. Journal of the American Planning Association, 80(3), 218-238.

Stevens, M. R., Park, K., Tian, G., Kim, K., \& Ewing, R. (2019). Why do some articles in planning journals get cited more than others? Journal of Planning Education and Research. https://doi.org/10.1177/ $0739456 \times 19827083$

Stiftel, B., Rukmana, D., \& Alam, B. (2004). A national research council-style study. Journal of Planning Education and Research, 24(1), 6-22.

Thelwall, M., Tsou, A., Weingart, S., Holmberg, K., \& Haustein, S. (2013). Tweeting links to academic articles. Cybermetrics: International Journal of Scientometrics, Informetrics and Bibliometrics, 17, 1-8.

Veletsianos, G., \& Kimmons, R. (2013). Scholars and faculty members' lived experiences in online social networks. The Internet and Higher Education, 16, 43-50.

Weller, K., Dröge, E., \& Puschmann, C. (2011). Citation analysis in Twitter: Approaches for defining and measuring information flows within Tweets during scientific conferences. Semantic Scholar. Retrieved from https://www.semanticscholar. org/paper/Citation-Analysis-in-Twitter\%3AApproaches-for-and-Weller-Dr\%C3\%B6ge/ 7f6bf1b22c2e6cd5c7062952cc51b03b4aafdb9c

Weller, M. (2011). The digital scholar: How technology is transforming scholarly practice. London: A\&C Black.

\section{About the Author}

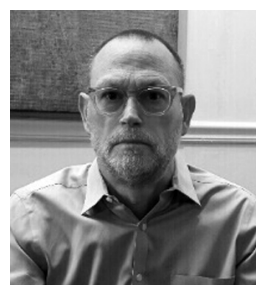

Thomas W. Sanchez earned his PhD in City Planning from Georgia Tech and is a Professor of Urban Affairs and Planning at Virginia Tech in the National Capital Region (Washington, DC/Northern Virginia). Sanchez is Editor-in-Chief of Housing Policy Debate, an international journal on the topics of housing and community development policy. He conducts research in the areas of transportation, housing, social justice, technology, and scholarly impact. 